\title{
LATERAL RELEASE FOR RECURRENT DISLOCATION OF THE PATELLA
}

\author{
D. J. DANDY, D. GRIFFITHS
}

From Newmarket General Hospital, Suffolk

\begin{abstract}
We reviewed 41 knees after arthroscopic lateral release for recurrent dislocation of the patella at a mean follow-up of four years, and graded the results according to the criteria of Crosby and Insall (1976).

There were no dislocations after operation in 28 knees (68\%); the less satisfactory results were in patients with subluxation of the patella on extension of the knee and those with generalised ligamentous laxity. There were no complications. A characteristic and previously unreported lesion of the patellar surface was seen in eight of the $\mathbf{4 1}$ knees.

The results of lateral release are better than those reported for other techniques. This treatment, by either open or arthroscopic methods, is recommended.
\end{abstract}

Many factors contribute to patellar dislocation, including generalised ligamentous laxity, dysplasia of the patella or the femoral condyles, genu valgum, tight lateral bands and patella alta. Many operations have been described for its treatment (Goldthwait 1904; Hauser 1938; West and Soto-Hall 1958; Baker et al. 1972; Madigan, Wissinger and Donaldson 1975). These include both proximal and distal realignment of the extensor mechanism, and most involve considerable surgical trauma, a large scar and prolonged rehabilitation.

The disability from recurrent dislocation of the patella is variable and the morbidity of operation may be greater. The complications of operation include osteoarthritis of the patellofemoral joint (Hampson and Hill 1975), loss of flexion, tenderness over screw or staple fixation, detachment of the patellar tendon (Crosby and Insall 1976) and genu recurvatum after distal realignment before growth is complete (Fielding, Liebler and Tambakis 1960; Pappas, Anas and Toczylowski 1984).

Lateral release of the extensor mechanism, whether by open operation or arthroscopic, offers more rapid rehabilitation, less surgical trauma, and fewer complica-

D. J. Dandy, FRCS, Consultant Orthopaedic Surgeon Newmarket General Hospital, Exning Road, Newmarket, Suffolk CB8 $7 \mathrm{JG}$, England.

D. Griffiths, MB, BCh, Senior House Officer

Addenbrooke's Hospital, Hills Road, Cambridge CB2 2QQ, England.

Correspondence should be sent to Mr D. J. Dandy.

(C) 1989 British Editorial Society of Bone and Joint Surgery

$0301-620 \mathrm{X} / 89 / 1018 \$ 2.00$

$J$ Bone Joint Surg [Br] 1989;71-B:121-5. tions. However, the results are not all satisfactory; we have therefore attempted to identify clinical and radiological features associated with a poor result. All the reported operations were undertaken to stabilise the patella, not to relieve non-specific anterior knee pain. We have also reviewed other reported results and made comparisons where the criteria of assessment made this possible.

\section{PATIENTS AND METHODS}

Between 1979 and 1986, a total of 40 patients had arthroscopic lateral release of the extensor mechanism for recurrent dislocation of the patella. Six patients had bilateral release, so there were 46 operations. Of these, 35 patients $(87 \%)$ with 41 operated knees were traced and reviewed. The average age at operation was 20.5 years (range eight to 40 years). There were 25 female patients (29 knees) and 10 males (12 knees). Patients were reviewed by clinical examination or postal questionnaire. The mean length of follow-up was 48.4 months (range 12 to 96 months).

Indications for operation. All patients had had at least three complete lateral dislocations of the patella; the patella had been seen or felt to lie on the lateral aspect of the femur. Subluxation or giving-way was not counted as a dislocation. All patients had had some conservative treatment, including physiotherapy, before operation. Arthroscopic lateral release was performed as the first operation in all patients with these indications during the study period until September 1981, when patients with subluxation of the patella on extension (Dandy 1971) 
were excluded because of unsatisfactory early results in three patients with this condition. None of the operations was for patellar pain.

Exclusions. Patients who had undergone a previous operation for patellar instability or an internal derangement, or had suffered major trauma to the knee, were excluded.

Pre-operative findings. All patients had some degree of apprehension when the patella was pushed laterally. Three patients (five knees) had gross generalised ligamentous laxity by the criteria of Carter and Sweetnam (1958), and three patients (four knees) had nailpatella syndrome with dysplastic patellae. One of these patellae dislocated completely with every flexion of the knee. Abnormalities were noted on the articular cartilage of the patellar surface at arthroscopy in 17 of the 41 knees.

Technique of operation. Arthroscopic examination is performed through a standard anterolateral approach (Dandy 1984). After removing the arthroscope a Smillie knife is inserted through the anterolateral incision and the lateral portion of the extensor mechanism is released from the level of the tibial plateau to $4 \mathrm{~cm}$ above the patella. The line of incision is kept as close as possible to the patellar tendon and patellar margin, but care is taken to avoid the quadriceps tendon. The synovium is also incised. The line of capsular incision is infiltrated with bupivacaine (Marcaine) and adrenalin and the arthroscope is re-inserted to confirm that the line of incision has extended into the belly of vastus lateralis.

A suction drain is then placed in the line of incision and a pressure dressing applied. The drain is removed when drainage has ceased or at 24 hours, whichever is sooner, and the patient encouraged to lift the straight leg, flex the knee and walk, taking full weight on the leg. The patient is discharged from hospital within 48 hours but a pressure dressing is retained for 10 days. The knee is not immobilised and all patients were able to lift the extended leg and flex to $90^{\circ}$ within one week. The operations were performed by DJD.

Assessment. The results of operation were assessed by the criteria of Crosby and Insall (1976):

Excellent - No pain, normal activities including all sports, full range of movement, knee subjectively normal.

Good - Occasional discomfort, feeling of stiffness, or instability, no participation in contact sports, slight loss of flexion, knee considered improved by the patient.

Fair/poor - Pain most of the time, symptoms altered but include recurrent subluxation or significant loss of flexion, further surgical treatment required in some instances.

Worse - Pain increased, displacement more frequent.

Patients were also asked to decide whether their patella felt completely stable; or had occasionally felt insecure but had never dislocated; or had dislocated at least once since operation. A radiological assessment of the height of the patella was made, using the criteria of Insall and Salvati (1971) and of Blackburne and Peel (1977).

\section{RESULTS}

The clinical results are set out in Table I.

Articular cartilage. Parallel longitudinal striations were seen on the patellar surface in eight of the 41 knees. The striations extended obliquely through the articular surface to give a characteristic appearance of interleaved strips (Fig. 1). Other lesions of the articular surface were

Table I. Clinical results of arthroscopic lateral release assessed by the criteria of Crosby and Insall (1976)

\begin{tabular}{|c|c|c|c|c|c|}
\hline \multirow[b]{2}{*}{ Clinical features } & \multirow[b]{2}{*}{$\begin{array}{l}\text { Number } \\
\text { of knees }\end{array}$} & \multicolumn{4}{|c|}{ Result, number and percentage } \\
\hline & & Excellent & Good & $\begin{array}{l}\text { Fair/ } \\
\text { poor }\end{array}$ & Worse \\
\hline Subluxation on extension & 4 & 0 & 1 & 1 & 2 \\
\hline Generalised ligament laxity & 5 & 0 & 5 & 0 & 0 \\
\hline Striations on patellar surface & 8 & 3 & 4 & 1 & 0 \\
\hline Other articular cartilage lesions & 9 & 4 & 4 & 1 & 0 \\
\hline Normal articular cartilage & 24 & 938 & 1354 & 1 & 1 \\
\hline Nail-patella syndrome & 4 & 3 & 1 & 0 & 0 \\
\hline All knees & 41 & 1639 & 2151 & 2 & 2 \\
\hline Excluding patients with subluxation on extension & 37 & 1646 & 2054 & 1 & 0 \\
\hline $\begin{array}{l}\text { Excluding patients with subluxation on extension } \\
\text { or generalised ligament laxity }\end{array}$ & 32 & 1650 & 1547 & 1 & 0 \\
\hline
\end{tabular}



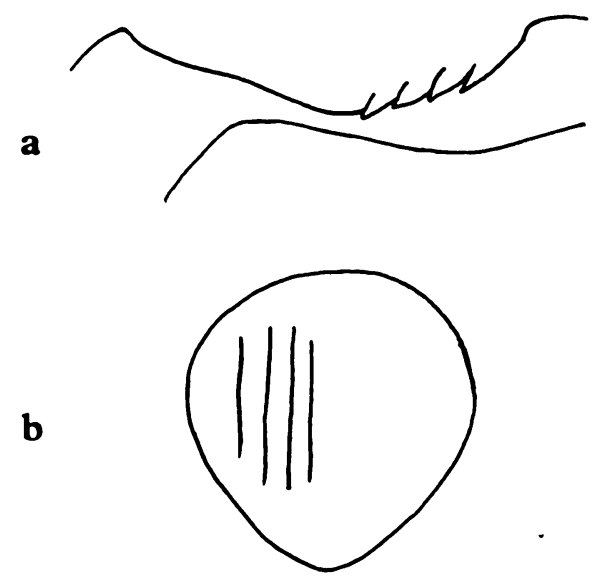

Fig. 1

Diagram of a horizontal section (a) and a surface view (b) of the vertical striations on the medial facet of the patella.

seen in seven of the other patients. Two of these were Grade 2 changes (Dandy 1987), four were Grade 1 and one patient had an old osteochondral fracture. Patients with articular surface defects had a slightly smaller proportion of excellent results than those with a normal articular surface (Table I).

Generalised ligamentous laxity. None of the five knees in three patients with generalised ligamentous laxity achieved a good result. Four patellae had continued to dislocate after the operation, though less frequently. One patella felt unstable but the patient had had no dislocation.

Height of the patella. The mean Insall and Salvati index for patella alta was 0.72 (normal 1). The mean score in the excellent and good categories was 0.74 and in the fair/poor and worse groups, 0.73 . The Blackburne and Peel index for the whole group was 1.1 (normal 0.8, range 0.55 to 1.06 ). The score in the excellent and good category was 1.13 and in the fair/poor and worse, 1.1. There was no correlation between the clinical result and the radiographic indices of the patellar height.

Nail-patella syndrome. Three of the four patients with dysplastic patellae associated with the nail-patella syndrome achieved excellent results. The fourth patient, whose patella had dislocated completely with every flexion of the knee, had a good result.

Subluxation on extension. Of the four patients with subluxation on extension, two were worse, one had a poor result and the other was good. One of these patients was the youngest in the series, eight years old at the time of operation, and had disabling dislocation both before and after lateral release. She later had a semitendinosus tenodesis, performed before her skeletal maturity.
Poor results. Three of the four patients with fair/poor or worse results had subluxation on extension. The remaining patient underwent operation on both knees as separate procedures. One knee showed an old osteochondral fracture of the patella but achieved a good result. The other knee, which had a normal patella, achieved only a fair/poor result and was the only knee in the series to require transposition of the tibial tubercle. No explanation was found for this difference.

Stability. The patients reported that 18 patellae $(44 \%)$ felt stable and had undergone no more dislocations since operation. Ten patellae $(24 \%)$ felt occasionally insecure or unsteady but not dislocated, and two of these patients considered their knees were "excellent" on the criteria of Crosby and Insall (1976). Thirteen patellae (32\%) had dislocated at least once, most in the first few months after operation. Ten of these became stable and achieved a good result.

Complications. No patient had a haemarthrosis and no other complications were encountered. One patient developed reflex sympathetic dystrophy five years after operation, though the result until then had been excellent; we did not consider this to be a complication of the operation.

\section{DISCUSSION}

Our experience of arthroscopic lateral release for recurrent dislocation of the patella is very similar to that of Chen and Ramanathan (1984), who found excellent results in over $40 \%$ of patients using the criteria of Crosby and Insall (1976). This figure compares favourably with the results of Crosby and Insall themselves, who reported only 7 and $8 \%$ of patients with excellent results after proximal realignment and tibial tubercle transposition respectively. We divided the synovium in our patients while Chen and Ramanathan left it intact. We extended the capsular incision to $4 \mathrm{~cm}$ above the upper pole of the patella, while Chen and Ramanathan extended it above the patella for a distance equal to the measured length of the patella. Neither of these differences appear to have affected the results.

The grades of "excellent" and "good" in the Crosby and Insall grading are misleading. Thirteen patellae in our series $(32 \%)$ dislocated at least once after operation, but 10 of these still achieved a "good" grade. Similarly, the fair/poor results with pain most of the time and recurrent subluxation could better be described as failures. Nevertheless, the Crosby and Insall grading is widely used and allows series to be compared.

Other authors have used different criteria. Bowker and Thompson (1964) also had $7 \%$ of excellent results after tibial tubercle transposition, but others reported that up to $43 \%$ of knees had no pain or tenderness, and a full range of movement after tibial tubercle transfer 
(Table II). It is likely that these differences lie in the stringency of the criteria used, particularly as Hampson and Hill (1975) found a high incidence of secondary osteoarthritis after tibial tubercle transposition. Madigan et al. (1975) had $47 \%$ of excellent results by their own criteria after vastus medialis advancement but there were $42 \%$ of poor results. On the basis of these figures, the results of lateral release are superior; we could find no reports of techniques which offered results approaching those of lateral release.

Anterior compartment syndrome (Wall 1979), genu recurvatum (Harrison 1955; Pappas et al. 1984), secondary osteoarthritis and (Hampson and Hill 1975; Crosby and Insall 1976), pain over the tibial tubercle (Harrison 1955; Chrisman, Snook and Wilson 1979) have all been reported after tibial tubercle transposition. No complications were encountered in our series or in that of Chen and Ramanathan (1984) but some have been reported to occur after arthroscopic lateral release (McGinty and McCarthy 1981; Metcalf 1982; DeLee 1985).

The worst results in our series were in patients whose patellae dislocated in flexion and subluxed on extension of the knee (Dandy 1971). We now consider that this feature is a contra-indication to lateral release. Generalised ligamentous laxity (Carter and Sweetnam 1958) was also associated with less satisfactory results. None of the five knees in three patients with this condition achieved an excellent result because the patella continued to feel unstable, but all achieved a good result and none considered their symptoms bad enough to justify a further procedure. When the knees which showed subluxation of the patella on extension of the knee, and patients with generalised ligamentous laxity were excluded from the calculations, $97 \%$ of our patients had an excellent or good result by the Crosby and Insall criteria (Table II).

Four patients with the nail-patella syndrome and dysplastic patellae all had an excellent or good result, including one whose patella had dislocated with every flexion of the knee. Accordingly, we do not regard a dysplastic patella as a contra-indication to lateral release.

The result in patients with damaged articular cartilage (Table I) was slightly less satisfactory than in patients with normal articular cartilage but the difference was not marked. The characteristic appearance of interlocking vertical striations seen on eight patellae has been described as the "Sydney Opera House Sign" (Dandy 1984); it has only been seen in patients with unstable or tilted patellae. The striations are probably produced during dislocation or reduction of the patella.

We conclude that lateral release of the patella is the treatment of choice for patients with recurrent dislocation of the patella, provided that the patella does not sublux laterally on extension of the knee. Patients with generalised ligamentous laxity are likely to do less well, but the operation is nevertheless considered to be successful by patients with this condition. There is no reason to suppose that arthroscopic lateral release has anything more than a cosmetic advantage over an open operation, and it has the disadvantage that bleeding from the superior lateral geniculate artery cannot easily be controlled. It may be that open lateral release through a $2 \mathrm{~cm}$ incision, which allows control of bleeding from the superior lateral geniculate artery will eventually prove to be the treatment of choice.

No benefits in any form have been received or will be received from a commercial party related directly or indirectly to the subject of this article.

Table II. Results of treatment by different techniques

\begin{tabular}{|c|c|c|c|c|c|c|c|}
\hline \multirow[b]{2}{*}{ Authors } & \multirow[b]{2}{*}{ Operation } & \multirow[b]{2}{*}{$\begin{array}{l}\text { Number of } \\
\text { patients }\end{array}$} & \multirow[b]{2}{*}{$\begin{array}{l}\text { Follow-up } \\
\text { (months) }\end{array}$} & \multicolumn{4}{|c|}{ Result as percentage } \\
\hline & & & & $\begin{array}{l}\text { Excellent } \\
\text { (using criteri }\end{array}$ & $\begin{array}{l}\text { Good } \\
\text { ia of Crosby }\end{array}$ & $\begin{array}{l}\text { Fair/ } \\
\text { poor } \\
\text { and Insall) }\end{array}$ & Worse \\
\hline Crosby and Insall 1976 & $\begin{array}{l}\text { Tibial tubercle transfer } \\
\text { Proximal realignment }\end{array}$ & $\begin{array}{l}69 \\
12\end{array}$ & $\begin{array}{l}96 \\
96\end{array}$ & $\begin{array}{l}7 \\
8\end{array}$ & $\begin{array}{l}52 \\
67\end{array}$ & $\begin{array}{l}21 \\
17\end{array}$ & $\begin{array}{r}10 \\
8\end{array}$ \\
\hline Chen and Ramanathan 1984 & Lateral release & 16 & 72 & 44 & 37 & 13 & 6 \\
\hline \multirow[t]{2}{*}{ Dandy and Griffiths 1989} & $\begin{array}{l}\text { Lateral release } \\
\text { Excluding subluxation on extension and } \\
\text { generalised ligament laxity }\end{array}$ & $\begin{array}{l}41 \\
32\end{array}$ & $\begin{array}{l}48 \\
48\end{array}$ & $\begin{array}{l}38 \\
50\end{array}$ & $\begin{array}{l}51 \\
47\end{array}$ & $\begin{array}{l}5 \\
3\end{array}$ & $\begin{array}{l}5 \\
0\end{array}$ \\
\hline & Tibial tubercle transfer & 30 & 70 & $\begin{array}{l}\text { Excellent } \\
\text { (using other } \\
43\end{array}$ & $\begin{array}{l}\text { Good } \\
\text { criteria) } \\
47\end{array}$ & & \\
\hline Heywood 1961 & $\begin{array}{l}\text { Tibial tubercle transfer } \\
\text { Tibial tubercle transfer } \\
\text { Patellectomy }\end{array}$ & $\begin{array}{l}52 \\
31 \\
29\end{array}$ & $\begin{array}{l}>12 \\
>72 \\
>12\end{array}$ & $\begin{array}{r}31 \\
29 \\
3\end{array}$ & $\begin{array}{l}17 \\
13 \\
21\end{array}$ & & \\
\hline Bowker and Thompson 1964 & Tibial tubercle transfer & 14 & 108 & 7 & 36 & & \\
\hline Madigan et al. 1975 & Vastus medialis advancement & 19 & 29 & 47 & II & & \\
\hline
\end{tabular}




\section{REFERENCES}

Baker RH, Carroll N, Dewar FP, Hall JE. The semitendinosus tenodesis for recurrent dislocation of the patella. J Bone Joint Surg [Br] 1972:54-B:103-9.

Blackburne JS, Peel TE. A new method of measuring patellar height. $J$ Bone Joint Surg [Br] 1977;59-B:241-2.

Bowker JH, Thompson EB. Surgical treatment-of recurrent dislocation of the patella : a study of forty-eight cases. J Bone Joint Surg [Am] 1964:46-A:1451-61.

Carter C, Sweetnam R. Familial joint laxity and recurrent dislocation of the patella. J Bone Joint Surg [Br] 1958;40-B:664-7.

Chen SC, Ramanathan EBS. The treatment of patellar instability by lateral release. J Bone Joint Surg [Br] 1984;66-B:344-8.

Chrisman OD, Snook GA, Wilson TC. A long-term prospective study of Hauser and Roux-Goldthwait procedures for recurrent patellar dislocation. Clin Orthop 1979;144:27-30.

Crosby EB, Insall J. Recurrent dislocation of the patella: relation of treatment to osteoarthritis. J Bone Joint Surg [Am] 1976:58-A:9-13.

Dandy DJ. Recurrent subluxation of the patella on extension of the knee. J Bone Joint Surg [Br] 1971 :53-B:483-7.

Dandy DJ. Arthroscopy of the knee : a diagnostic colour atlas. London: Butterworths, 1984.

Dandy DJ. Arthroscopic management of the knee. 2nd ed. Edinburgh, etc: Churchill Livingstone, 1987.

DeLee JC. Chairman, Committee on Complications of Arthroscopy Association of North America. Complications of arthroscopy and arthroscopic surgery: results of a national survey. $J$ Arthroscopic Rel Surg 1985;1:214-20.

Fielding JW, Liebler WA, Tambakis A. The effect of a tibial-tubercle transplant in children on the growth of the upper tibial epiphysis. $J$ Bone Joint Surg [Am] 1960;42-A :1426-34.
Goldthwait JE. Slipping or recurrent dislocation of the patella with the report of eleven cases. Boston Med Surg J 1904:150: 169-74.

Hampson WGJ, Hill P. Late results of transfer of the tibial tubercle for recurrent dislocation of the patella. J Bone Joint Surg $[\mathrm{Br}]$ 1975;57-B:209-13.

Harrison MHM. The results of a realignment operation for recurrent dislocation of the patella. J Bone Joint Surg [Br] 1955;37-B :559-67.

Hauser EDW. Total tendon transplant for slipping patella: new operation for recurrent dislocation of the patella. Surg Gynecol Obstet 1938;66:199-214.

Heywood AWB. Recurrent dislocation of the patella: a study of its pathology and treatment in 106 knees. $J$ Bone Joint Surg [Br] $1961: 43-B: 508-17$.

Insall J, Salvati E. Patella position in the normal knee joint. Radiology $1971 ; 101: 101-4$.

Madigan R, Wissinger HA, Donaldson WF. Preliminary experience with a method of quadricepsplasty in recurrent subluxation of the patella. J Bone Joint Surg [Am] 1975:57-A:600-7.

McGinty JB, McCarthy JC. Endoscopic lateral release: a preliminary report. Clin Orthop 1981:158:120-5.

Metcalf RW. An arthroscopic method for lateral release of the subluxating or dislocating patella. Clin Orthop 1982;167:9-18.

Pappas AM, Anas P, Toczylowski HM Jr. Asymmetrical arrest of the proximal tibial physis and genu recurvatum deformity. $J$ Bone Joint Surg [Am] 1984;66-A :575-81.

Wall JJ. Compartment syndrome as a complication of the Hauser procedure. J Bone Joint Surg [Am] 1979;61-A:185-91.

West F, Soto-Hall R. Recurrent dislocation of the patella in the adult : end results of patellectomy with quadricepsplasty. J Bone Joint Surg $[\mathrm{Am}] 1958 ; 40-\mathrm{A}: 386-94$. 